\title{
English orthographic forms affect $L 2$ English speech production in native users of a non-alphabetic writing system
}

Article

Accepted Version

Sokolović-Perović, M., Bassetti, B. and Dillon, S. (2020) English orthographic forms affect L2 English speech production in native users of a non-alphabetic writing system. Bilingualism: Language and Cognition, 23 (3). pp. 591-601. ISSN 1469-1841 doi:

https://doi.org/10.1017/S136672891900035X Available at https://centaur.reading.ac.uk/85013/

It is advisable to refer to the publisher's version if you intend to cite from the work. See Guidance on citing.

To link to this article DOI: http://dx.doi.org/10.1017/S136672891900035X

Publisher: Cambridge University Press

All outputs in CentAUR are protected by Intellectual Property Rights law, including copyright law. Copyright and IPR is retained by the creators or other copyright holders. Terms and conditions for use of this material are defined in the End User Agreement. 


\section{CentAUR}

Central Archive at the University of Reading

Reading's research outputs online 
Short title: Orthographic effects on L2 speech production

English orthographic forms affect L2 English speech production in native users of a non-alphabetic writing system*

Mirjana Sokolović-Perović ${ }^{1}$, Bene Bassetti ${ }^{2}, \&$ Susannah Dillon ${ }^{1}$

${ }^{1}$ University of Reading, UK ${ }^{2}$ University of Birmingham, UK

Address for Correspondence

Mirjana Sokolović-Perović

School of Psychology and Clinical Language Sciences

University of Reading

Harry Pitt Building

Earley Gate

Reading

RG6 6AL

E-mail: m.sokolovic@ @reading.ac.uk

* This work was partially supported by a Leverhulme Trust Research Grant [grant number: RPG 2013 180] awarded to Bene Bassetti and Jackie Masterson.

We are grateful to Dr Tania Cerni for advice on the statistical analysis, to Dr Rosalba Nodari for contributing to the acoustic analysis, and to all participants. 


\begin{abstract}
There is growing evidence that the orthographic forms (spellings) of second language words affect second language (L2) speech production, but it is not known whether orthography affects L2 phonology in native users of a non-alphabetic writing system. To answer this question, this study tested the effects of number of letters on the duration of consonants and vowels in the English $\mathrm{L}_{2}$ speech production of Japanese-English sequential bilinguals. Japanese $_{\text {L1-English }}$ bilinguals and English native speakers (both $n=16$ ) performed a delayed word repetition task, producing 16 English word pairs in which the same consonant or vowel was spelled either with a single letter or with double letters, as in city-kitty. The bilinguals produced the same English sound as longer or shorter depending on the number of letters in its spelling, confirming that L2 orthographic forms affect L2 speakers' phonological representations of L2 words even when their L1 writing system is not alphabetical.
\end{abstract}

Keywords: bilingualism, speech production, orthographic effects, L2 phonology, English as a second language, Japanese 


\section{Introduction}

Recent research shows that second language (L2) orthography - the way L2 sounds and words are represented in spelling - can affect the way L2 speakers produce and perceive L2 sounds. However, research has so far focused on the effects of spelling in L2 learners who are native users of alphabetic writing systems. The present paper therefore investigated whether the spellings of English sounds can affect speech production in L2 speakers who are native users of a non-alphabetic writing system.

\subsection{Effect of second language orthography on second language phonology}

There is increasing evidence that L2 orthography can affect L2 speakers' production and perception of L2 sounds (for reviews, see Bassetti, 2008; Bassetti, Escudero, \& Hayes-Harb, 2015). Although some studies reported no orthographic effects (Escudero, 2015; Escudero \& Wanrooij, 2010; Simon, Chambless, \& Alves, 2010) and others found facilitative effects (Escudero, Hayes-Harb, \& Mitterer, 2008; Showalter \& Hayes-Harb, 2013), many studies show that L2 orthographic forms can lead to nonnative-like pronunciations, such as the addition, deletion, and - more often - the substitution of target sounds (Bassetti, 2008; Davidson, 2010; Escudero, Simon, \& Mulak, 2014; Hayes-Harb, Nicol, \& Barker, 2010; Pytlyk, 2011; Young-Scholten \& Langer, 2015). Second language speakers can add sounds that are represented in the orthographic forms of L2 words; for instance, they may pronounce comb /kəum/ as [kəumb] (Bassetti \& Atkinson, 2015). They also omit sounds that are not represented in the L2 orthographic forms. For instance, learners of Chinese as a foreign language produced the triphthong /uei/ in /suei/ "year of age" correctly when it was spelled with three letters as <wei>, but as a diphthong */ui/ when spelled with two vowel letters as <sui> (Bassetti, 2007). The most widely studied orthographic effect on L2 phonology is 
SOUND SUBSTITUTION, whereby L2 speakers substitute the target sound with another sound, either from the target language or absent from the target language, because of its spelling. Examples of substitutions with other L2 sounds include the substitution of word-final [t] with

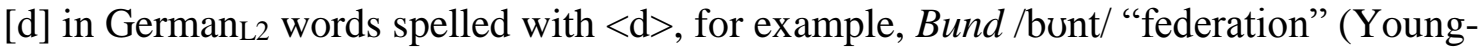
Scholten, 2002) or the substitution of a flap allophone of /t, d/ with [t], [ð] or [d] in American English $_{\mathrm{L} 2}$ words spelled with <t, tt, d, dd> (e.g., city, chatty, body, or buddy; Vokic, 2011). As an example of substitutions with sounds that do not exist in the target language, English $\mathrm{L}_{\mathrm{L}}$ beginner learners of Spanish $_{\mathrm{L} 2}$ produce [v] in Spanish $\mathrm{S}_{2}$ words spelled with $\langle\mathrm{v}\rangle$ (e.g., vulgar /bul'yar/ "vulgar"), even though this sound is not present in Spanish (Zampini, 1994).

Orthographic effects on L2 phonology can be intra- or inter-orthographic (Bassetti, 2017). An INTRA-ORTHOGRAPHIC EFFECT is when an L2 grapheme is phonologically recoded using L2 grapheme-phoneme correspondences (GPCs) - rules that govern how a unit of writing is recoded into a unit of sound. For instance, L2 speakers of German pronounced word-final $\langle\mathrm{d}\rangle$ as $[\mathrm{d}]$ (instead of $[\mathrm{t}]$ ), because in German $\langle\mathrm{d}\rangle$ generally represents the phoneme /d/, but not in word-final position (e.g., in Bund /bunt/ "federation"; YoungScholten, 2002). An INTER-ORTHOGRAPHIC EFFECT is when an L2 grapheme is recoded using L1 GPCs. For instance, native Italian speakers studying English sometimes realize $\langle w\rangle$ as [v] in words such as wood, because <v> represents /v/ in Italian loanwords such as <water> (/'vater/) and <watt> (/vat/; Bassetti \& Atkinson, 2015). Researchers have argued that many sound substitutions are caused by incongruences between L1 and L2 GPCs like this one, when a grapheme represents different phonemes in the two languages of an L2 speaker (Hayes-Harb et al., 2010). Various studies investigated the effects of L1-L2 grapheme incongruence, and consistently found that incongruence negatively affects L2 speech 
production (Escudero, 2015; Escudero, Hayes-Harb, \& Mitterer, 2008; Nimz, 2016; Pytlyk, 2011). Escudero, Simon, and Mulak (2014) manipulated congruency to compare the effects of congruent and incongruent graphemes on L2 word recognition in beginner and naïve listeners, and confirmed that congruent graphemes have a facilitative effect and incongruent ones have a negative effect.

Finally, with regards to the locus of orthographic effects on phonology, researchers working on native phonologies have proposed two main explanations. Some researchers have argued that these effects are due to the co-activation of the orthographic and phonological codes of a word during speech production (Muneaux \& Ziegler, 2004; Rastle, McCormick, Bayliss, \& Davis, 2011). Other researchers have argued that orthographic forms affect phonological representations, that is to say, the way a word is written affects its phonological code in the mental lexicon (Taft, 2006). However, it is not clear which of these explanations can best explain orthographic effects on L2 phonology. Bassetti (2017) argued that L2 orthographic forms are very likely to affect phonological representations, whereas coactivation of L2 orthographic forms is a less likely explanation because it would also require the co-activation and incorrect online application of L1 GPCs during L2 speech production. At any rate, research on L2 speech can contribute to understanding the nature of orthographic effects on phonology.

\subsection{Effects of number of letters on L2 sound length}

A series of studies by Bassetti and colleagues found that the number of letters in the spelling of an English sound affects the duration of the sound in the production of Italian L1 $_{\text {speakers }}$ of English ${ }_{\mathrm{L} 2}$ (Bassetti, 2017; Bassetti \& Atkinson, 2015; Bassetti, Sokolović-Perović, Mairano, \& Cerni, 2018). Unlike English, where consonant length is not contrastive, Italian has a phonological contrast between singleton and geminate (short and long) consonants 
(Laver, 1994). Singleton and geminate consonants distinguish minimal word pairs (two words that differ in one phoneme, Clark \& Yallop, 1995), such as cane /'kane/ "dog” and canne /'kan:e/ "reeds" (/:/ represents a long sound). Italian geminate consonants are represented with double consonant letters, for example, /n:/ in canne. Italian L1 speakers of English $_{\mathrm{L} 2}$ produced the same English consonant as longer when it was spelled with two letters (e.g., [t] in kitty) than one (e.g., in city; Bassetti, 2017). Homophonic English word pairs containing the same consonant spelled with a single letter or double letters were produced as minimal pairs distinguished by a singleton or geminate consonant; for instance, finish was produced with a singleton [n] (['finI $]]$ ) and Finnish with a geminate [n:] (['fin:I $]]$ ) (Bassetti et al., 2018). This means that Italian ${ }_{\mathrm{L} 1}$ speakers have established a phonological contrast between geminate and singleton consonants that does not exist in English and is based on the written forms of English words interpreted through their L1 knowledge.

While orthographic effects on consonant duration were clear, effects on vowel duration were more nuanced (Bassetti et al., 2018). Vowel length is not contrastive in either Italian or English, but English vowels can be long or short. English long vowels are typically represented by vowel digraphs; for instance, /i:/ is represented by double letters <ee> in sheep. However, long vowels can also be represented by a single letter, such as /i:/ in he and ski (Carney, 1994). Italians, who generally do not make the qualitative distinction between English tense and lax vowels, can distinguish these vowels using duration, and can rely on the number of letters in a vowel's spelling to determine its duration. Bassetti and Atkinson

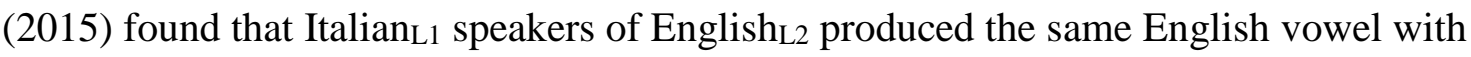
longer duration when it was spelled with double vowel letters (e.g., moon, /mu:n/) than when it was spelled with a single vowel letter (e.g., June, /dzu:n/). Bassetti and colleagues (2018) 
confirmed these results using homophonic word pairs distinguished by the number of letters in the spelling of the same long vowel, such as seen and scene (both /sinn/). Italians produced these words as non-homophonic (producing a longer vowel in seen than in scene), whereas native English speakers produced the two vowels with the same duration.

\subsection{Open questions in research on orthographic effects on L2 phonology}

In spite of the rapidly growing body of evidence, some aspects of orthographic effects on L2 phonology have not been investigated yet. First of all, only a limited range of languages and scripts have been researched, with the focus so far on European languages written in the roman alphabet. Further cross-linguistic research is needed in order to establish when orthographic effects are likely to happen. In particular, hardly anything is known about orthographic effects on L2 phonology in native users of a non-alphabetic writing system. At a more general level, English word spellings, which represent phonemes, may not influence L2 speakers whose L1 writing system represents syllables or morphemes rather than phonemes. At a more specific level, when the L2 speakers' native writing system is not alphabetical, there are no incongruences between the GPCs of the native orthography and of the L2 orthography. A few studies, mostly by Hayes-Harb and colleagues, investigated cross-scriptal orthographic effects; their focus was on the learning of sounds of a novel language through a novel orthography (Hayes-Harb \& Cheng, 2016; Pytlyk, 2011; Showalter, 2018; Showalter \& Hayes-Harb, 2015). A more recent study looked at cross-scriptal effects in English ${ }_{\mathrm{L} 1}$ learners of Russian $_{\text {L2 }}$ (Simonchyk \& Darcy, 2018), whose two writing systems are both alphabetic. There has been, to the best of our knowledge, no research on orthographic effects on L2 speech production in biscriptals whose L1 writing system is not alphabetic.

Second, there have been very few studies of experienced L2 speakers producing real L2 words. Researchers have rarely investigated orthographic effects on the speech production of 
bilinguals, focussing instead mostly on learners of novel languages (Davidson, 2010; HayesHarb et al., 2010; Pytlyk, 2011) and beginner L2 learners (Young-Scholten, 2002; Zampini, 1994). The few studies of experienced L2 speakers investigated the effects of orthography on the learning of pseudowords (Escudero et al., 2008; Piske, Flege, MacKay, \& Meador, 2002). Only a small number of recent studies have investigated orthographic effects on the production of real words in sequential bilinguals living in a target language environment (Bassetti et al., 2018; Vokic, 2011).

Given the absence of cross-scriptal research and the very limited research on sequential bilinguals, the present study aimed at investigating orthographic effects in

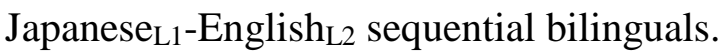

\subsection{Consonant and vowel length in Japanese and English}

In Japanese, length is contrastive in both consonants and vowels. The geminate-singleton opposition is used to distinguish minimal pairs such as /kata/ "frame" and /kat:a/ "bought" (Kawahara, 2015), and the opposition between short and long vowels is used to distinguish minimal pairs such as /to/ “door" and /to:/ "ten” (Kubozono, 2015a).

\section{Japanese and English consonants}

The consonant inventories of Standard Japanese and Standard British English both include the voiceless plosives /p, t, k/ (H. Okada, 1999; Roach, 2004), which were the object of the present study. Consonant length is not phonemic in English. Voiceless plosives can be geminated in Japanese (Kubozono, 2015a); voiced ones are only geminated in loanwords (Kawagoe, 2015; Otaka, 2009).

The primary acoustic correlate of gemination in Japanese is consonant duration: geminates are two to three times longer than singletons (Kawahara, 2015). Secondary 
correlates include durations of the preceding and the following vowel (Idemaru \& Guion, 2008; Kawahara, 2015), as well as non-durational correlates such as intensity, fundamental frequency fall across the surrounding vowels, and voice quality (Idemaru \& Guion, 2008).

\section{Japanese and English vowels}

Standard Japanese has five short monophthong vowels /i e a o u/ (pronounced [i e a o $u$ ]) and five corresponding long monophthongs /i: e: a: o: u:/ (Kubozono, 2015a; H. Okada, 1999). Long vowels are two to three times longer than short vowels (Hirata, 2004; Hirata \& Tsukada, 2009; Ueyama, 2000), but they do not differ in quality (Kubozono, 2015a; Tsukada, 2009a; Ueyama, 2003; but see Hirata \& Tsukada, 2009).

Standard British English has seven lax monophthongs /I e æ $\Lambda \mathfrak{D} \cup$ ə/ and five tense monophthongs /i: a: o: u: 3:/ (Roach, 2004). They differ in both quantity and quality: tense vowels are longer than lax vowels (Hillenbrand, 1995; Kondaurova \& Francis, 2010; Leung, Jongman, Wang, \& Sereno, 2016; Peterson \& Lehiste, 1960; Williams \& Escudero, 2014), and they are more peripheral (for example, /i:/ is higher and more front than /I/ Ladefoged \& Johnson, 2011; Peterson \& Barney, 1952).

\section{Sound length representation in written Japanese}

Japanese is written in a mixture of KANJI (characters), which are phonologically opaque, and KANA, generally called 'syllabaries': HIRAGANA is used for native words and KATAKANA for loanwords (Coulmas, 2003). Each kana symbol represents a mora; for instance, /hon/ is written with two kana symbols ほ /ho/ and $ん$ /n/ (Otake, 2015; Ueyama, 2000). Kana symbols are highly phonologically transparent. For instance, the mora $/ \mathrm{ka} /$ is always 
represented by the graphemes か in hiragana and $力$ in katakana, and vice versa. Other scripts include FURIGANA, which is used to gloss the pronunciation of kanji, and romanisation, which is used to input text in computers and other electronic devices.

Length is represented by the addition of a kana symbol (Laburne, 2012). Gemination is represented by a reduced-size TSU symbol before the consonant symbol ( $っ$ in hiragana and in katakana), as in the minimal pair おと/oto/ “sound” and おうと/ot:o/ "husband”. Vowel length is represented in hiragana by an additional vowel symbol after the first mora: for instance, the vowel symbol お /o/ distinguishes short and long vowel in the minimal pair とり /tori/ "bird” and とおり/to:ri/ "street”. In katakana it is represented by a line —, for instance, カー $/ \mathrm{ka:} /$ "car”.

\subsection{Phonology in Japanese ${ }_{L 1}$ speakers of English $_{L 2}$}

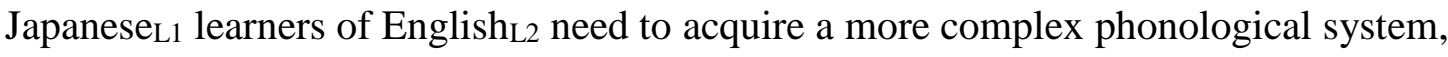
including consonantal contrasts and the qualitative distinction in vowels that do not exist in their L1. Most research on Japanese speakers' pronunciation of English consonants has focused on the ///-/r/ contrast (Aoyama, Flege, Guion, Akahane-Yamada, \& Yamada, 2004). For vowels, most researchers investigated the lack of qualitative distinction between /I/ and /i:/, both generally produced as Japanese /i/ (Tsukada, 2009b; Ueyama, 2003), the consistent substitution of schwa with other vowels, and vowel epenthesis (for effects of orthography on these, see e.g., Detey \& Nespoulous, 2008; Dupoux, Kakehi, Hirose, Pallier, \& Mehler, 1999). These effects of L1 phonology may in fact be reinforced by Japanese orthographic input, as kana does not distinguish /1/-/r/ (e.g., both loanwords <glass> and <grass> are グラスin katakana; T. Okada, 2015). 
There is evidence that English orthography can affect pronunciation in Japanese 1 speakers of English 2 . For instance, Japanese learners of English ${ }_{\mathrm{L} 2}$, who often cannot distinguish $/ 1 /$ and $/ r$, can produce the correct sound if they know the word's spelling (Brown, 1998; Sheldon \& Strange, 1982). English orthography can also affect English L2 $_{\text {pronunciation indirectly, via }}$ the phonological and orthographic form of English loanwords. English consonants written with double letters can undergo gemination in loanwords; for example, inner /'Inə/ is adapted in Japanese with a geminate /n:/, becoming /in:a:/. Gemination can even distinguish minimal pairs of loanwords, such as /bagu/ "bug" and /bag:u/ "bag" (English /b^g/ and /bæg/ respectively; Kawagoe, 2015; Kubozono, 2015b). English tense and lax vowels can be adapted as the same vowel qualitatively, but with different duration; for instance, $/ \mathrm{I} /$ in pin /pIn/ is adapted as Japanese /i/ in the loanword /piN/, whereas /i:/ in key /ki:/ becomes /i:/ in the loanword /ki:/ (Irwin, 2011).

\subsection{The Present Study}

This study investigated for the first time whether L2 orthography affects L2 speech in biscriptal sequential bilinguals with a non-alphabetic L1 writing system, by testing the effects of number of letters in English word spellings on the duration of consonants and vowels in

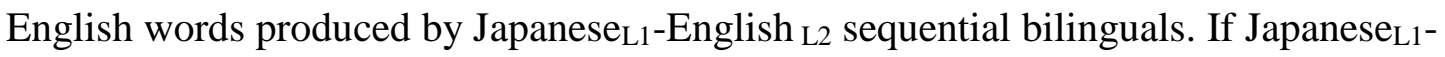
English $_{\mathrm{L} 2}$ bilinguals produce the same English sound as longer in English words spelled with double letters and as shorter in words spelled with a single letter, this would mean that English orthographic forms result in nonnative-like speech production in these biscriptal speakers of English ${ }_{\mathrm{L} 2}$. Previous research has demonstrated that Italian speakers of English $\mathrm{L}_{2}$ have established a long-short contrast in their L2 phonological systems that does not exist in 
English, and rely on orthographic forms to determine sound length: they produce the same English consonant or vowel as longer when it is spelled with a digraph than with a single letter, such as in Finnish vs. finish (Bassetti, 2017; Bassetti \& Atkinson, 2015; Bassetti et al., 2018). These effects are caused by the interaction between the phonological and orthographic systems of Italian and English. The present study is aimed at disentangling the respective effects of the native phonology and orthography as follows:

First, this study investigated orthographic effects on L2 phonology in native users of a non-alphabetic writing system. Previous findings of orthographic effects on L2 consonant duration were attributed to L2 speakers decoding L2 orthographic forms - specifically, number of letters - using their native GPC rules, where double letters represent geminate consonants (Bassetti, 2017; Bassetti et al., 2018). However, Italian and English share the same alphabet. It is not clear whether the number of letters in English spelling affects sound duration in native users of a non-alphabetic writing system. There may well be no orthographic effects when the two languages of an L2 speaker use different scripts, because, as argued by Showalter \& Hayes-Harb (2015), such speakers do not need to override L1 grapheme-phoneme correspondences. Research on learners of novel scripts or novel symbols (Hayes-Harb \& Cheng, 2016; Pytlyk, 2011; Showalter \& Hayes-Harb, 2015), while important to establish how orthography can affect the early stages of L2 learning, cannot answer this question. Cross-scriptal evidence from experienced L2 speakers from a non-alphabetic background is needed to extend findings of orthographic effects on phonology beyond native users of alphabetic writing systems.

Second, the present study investigated native speakers of a language that has contrastive length in both consonants and vowels. Previous research on number of letters effects investigated Italian native speakers, for whom consonant length is contrastive, but vowel length is not (Bassetti, 2017; Bassetti \& Atkinson, 2015; Bassetti et al., 2018). 
Orthographic effects were found on the duration of both English $\mathrm{L} 2_{2}$ consonants and vowels, however the ratio of long to short vowels (between 1.2 and 1.4) was somewhat smaller than the ratio normally found for English tense vs. lax vowels (between 1.2 and 1.7). This may be due to the interaction between orthographic input (double letters) and acoustic input (no vowel duration differences), or it could be caused by the absence of contrastive length for vowels in their native language. To further clarify the nature of these orthographic effects, it is necessary to test English $\mathrm{L}_{2}$ speakers whose native language has contrastive vowel length.

This study aimed at testing whether L2 orthographic forms can result in a length contrast in the L2 production of both consonants and vowels in native users of a language with contrastive consonant and vowel length and with a non-alphabetic writing system. Japanese was chosen because it has contrastive consonant and vowel length, and a nonalphabetic writing system where long sounds are represented consistently in the orthography but not by means of letter digraphs. Furthermore, native Japanese speakers may be affected by L2 orthographic forms, because kana is highly phonologically transparent, and native users of phonologically transparent alphabetic writing systems are likely to rely on orthographic forms to establish the pronunciation of a second language (Erdener \& Burnham, 2005). However, it is not clear whether this reliance on L2 orthography is found in native users of a transparent writing system that is not alphabetical. Finally, participants were instructed sequential bilinguals. They had completed their English language instruction, and were living and using English in an English-speaking environment. This is because research on experienced L2 speakers is needed to show whether orthography has long-term effects beyond the early stages of learning and the instructed environment investigated by most researchers so far (for studies of sequential bilinguals in naturalistic environments, see Bassetti et al., 2018, and Vokic, 2011; for the distinction between L2 learner and bilingual/L2 user, see e.g., Cook, 2002). 
This study investigated whether Japanese L1-English $_{\text {L2 }}$ speakers would produce the same English sound as longer when spelled with double letters than when spelled with a single letter. Bilinguals were compared with a group of native British English speakers. Participants performed a DELAYED WORD REPETITION TASK, whereby they heard a native speaker's pronunciation of a phrase and repeated a target word. Delayed repetition tasks have been used to investigate L2 speech production (e.g., Flege, Munro, \& MacKay, 1995), including orthographic effects on L2 speech production (Bassetti, 2017; Bassetti \& Atkinson, 2015). In the task, the orthographic input was read out loud and the output was spoken, in order to test orthographic effects on phonology in the absence of orthography. This is because orthographic effects may be stronger with than without orthographic input in beginners and in learners of novel languages or novel words (Rafat, 2016; Young-Scholten, 2002; Zampini, 1994). However, this may not apply beyond the early stages of learning in experienced L2 speakers producing real L2 words (Bassetti et al., 2018).

If Japanese-English bilinguals systematically produce the same English $\mathrm{L}_{2}$ sound as longer when spelled with a digraph than when spelled with a single letter, this would indicate that they have established a contrast in their L2 phonological system that does not exist in the phonological systems of native English speakers. This would show that orthographic forms affect L2 phonology in L2 speakers with a non-alphabetic L1 writing system, a population that has hitherto not been studied.

\section{Methods}

\subsection{Participants}

Participants were 16 Japanese-English bilinguals and 16 native speakers of British English, with similar gender and age compositions (females = 13 in both groups; age: $M_{\text {bilinguals }}=$ 
34.94 years, $\left.S D=8.11 ; M_{\text {natives }}=33.81, S D=16.77\right)$ and no known language, visual or reading difficulties.

The native English participants were speakers of Southern British English. The Japanese-English participants were predominantly speakers of Standard Japanese $(n=7)$ or the Osaka variety ( $n=6$; other varieties: Shizuoka, Hokkaido and Iwami, all $n=1$ ), with no knowledge of other languages with contrastive length. They had studied English as an academic subject for an average of nine years and six months, with a mean age of onset of acquisition of around 11 years. While in school, two-thirds had studied only with non-nativespeaking teachers $(n=10)$, the rest with native English teachers or both. Participants had been living in an English-speaking country for an average of nearly five years, and about two-thirds were postgraduate students at a British university $(n=10)$. They rated their English proficiency on average as 3.75 on a 7 -point scale, where $7=$ native-like. Participants reported spending more time reading than listening to English (on average 9.44 hours/week vs. 3.14 hours/week). They considered a native-like pronunciation as quite important, with a mean rating of 5.13 on a 7 -point scale, where $7=$ very important. Among the students, nine had taken an IELTS test, with the average score of 6.5 (The International English Language Testing System, or IELTS, uses a nine-band scale with levels of proficiency ranging from non-user [band score 1] to expert user [band score 9]). Table 1 presents a summary of participant details for the Japanese-English bilingual group. 
Table 1. Summary of participant details for Japanese-English bilinguals.

\begin{tabular}{lllll}
\hline Factor & N & Mean & SD & Range \\
\hline Age (years) & 16 & 34.94 & 8.11 & $22-49$ \\
Time spent studying English (years) & 16 & 9.53 & 4.23 & $2-20$ \\
Age of acquisition onset (years) & 16 & 11.32 & 1.68 & $8-13.42$ \\
Time spent in an English-speaking country (years) & 16 & 4.76 & 6.64 & $3-25$ \\
Self-rated proficiency in English (scale 1-7) & 16 & 3.75 & 1.34 & $2-6$ \\
Time spent reading in English (hours/week) & 16 & 9.44 & 8.72 & $0-35$ \\
Time spent listening to English (hours/week) & 16 & 3.14 & 8.02 & $0-30$ \\
Importance of native-like pronunciation (scale 1-7) & 16 & 5.13 & 1.20 & $2-6$ \\
Average IELTS score & 9 & 6.5 & 0.56 & $5-7$
\end{tabular}

\subsection{Materials}

Materials were 32 English words: nine word pairs containing a target consonant and seven containing a target vowel. Consonant pairs and carrier phrases were taken from Bassetti (2017), and vowel pairs and carrier phrases from Bassetti and Atkinson (2015). A full list of word pairs and the corresponding carrier phrases is provided in the Appendix.

For target consonants, there were three target word pairs for each of the English voiceless plosives $/ \mathrm{p}, \mathrm{t}, \mathrm{k} /$. Within each word pair, the target consonant occurred in the same intervocalic contexts and within the same word stress patterns, but it was spelled with a single letter in one word (C-consonant) and with double letters in the other one (CC-consonant), such as /t/ in city and kitty (for more information about the words, including frequencies, see Bassetti, 2017). Among the CC-words, two were loanwords in Japanese: one contained a geminate in Japanese (floppy) and one contained a singleton consonant (kitty).

The target vowels were: /i:/ (five word pairs), /o:/ and /u:/ (both one word pair; vowel choice reflects the relative frequencies of the GPCs for $\langle e e>$ and $\langle 00\rangle$ in the English 
lexicon). Within each pair, the target vowel was spelled with a single (or zero) letter (Vvowel) or with double letters (VV-vowel), such as in the pair June-moon (/dzuin/ - /mu:n/).

There were three homophonic pairs, such as scene-seen (both /si:n/) and four near-minimal pairs, in which the target vowel occurred in the same rime, that is to say it was word-final or it was followed by the same consonant in both words, such as June-moon (for more information about the words, see Bassetti \& Atkinson, 2015).

Each word was presented orally within a six-word phrase, recorded by a male native speaker of Standard British English. A truncated version of each phrase was obtained by deleting the target word and all words following it. Each target word was also introduced by an image.

\subsection{Task and procedure}

Participants performed a delayed word repetition task, followed by a spelling task.

In the delayed word repetition task (Bassetti, 2017), a phrase and a related image were used to help participants recognise the target word. First, an image appeared in the centre of the screen. The image illustrated the meaning of the phrase that followed (for instance, an image of condiments). After clicking on an on-screen button with the mouse, the participant heard over headphones a pre-recorded phrase, such as Salt and pepper, oil and vinegar. The phrase and the related image helped participants recognise the target word, in this case pepper. Before repeating the phrase, the participant counted aloud backward from seven to one in English. This distractor task was used to eliminate traces of the phonological input from memory. After repeating the phrase, the participant clicked on another on-screen button, and heard a truncated version of the phrase, such as Salt and. They then had to produce the 
first missing word (the target) in the carrier sentence The word ... is missing three times (e.g., The word pepper is missing). The carrier sentence was used to place the target word in the nuclear position within the intonational phrase. The three repetitions were used to obtain a reliable measure of sound duration. For a graphic representation of the task, see Bassetti (2017).

A spelling task was used to test the participants' knowledge of the spelling of the 32 target words. This is because effects of number of letters were only expected when participants knew the correct number of letters in the spelling of the target sound. For each word, the participant saw the same image as in the word repetition task. Upon clicking on an on-screen button, they heard a recording of the word produced in isolation by the same male native speaker and wrote the spelling on paper. The words were presented in random order.

Participants were tested individually in a sound-attenuated booth. A researcher provided instructions before each task and supervised four practice trials before the word repetition task. Stimuli were presented on a MacBook Air laptop running PsyScope X (Cohen, MacWhinney, Flatt, \& Provost, 1993) and over headphones. The responses were recorded using the Praat software (Boersma \& Weenink, 2012) via an AKG D80 microphone connected to a computer. Participation was voluntary and unpaid.

\subsection{Data analysis}

For each of the target sounds, durations were measured from spectrogram and waveform displays in Praat (Boersma \& Weenink, 2012), using standard segmentation procedures (Foulkes, Docherty, \& Jones, 2010; Keating, Linker, \& Huffman, 1983; Turk, Nakai, \& Sugahara, 2006). Plosive duration was measured as the duration of the closure, which is the main phonetic cue to gemination in Japanese plosives (Kawahara, 2015). Closure duration was measured from the offset of the preceding vowel, characterised by a drop in amplitude 
and a loss of the second and higher formants, to the onset of the plosive release. If there were multiple bursts, the first one was taken as the onset of the release. Pre-aspiration, which occurred frequently in the production of the native English group, was not included in closure duration (Foulkes \& Docherty, 2006). For vowels, duration was measured from the onset of the clearly defined formant pattern, in particular F2 and the higher formants, accompanied by an amplitude increase and a complex waveform display. The offset of the vowels was marked at a drop in amplitude and the cessation of the second and higher formants. In words where the target vowel was followed by the nasal /n/ or the fricative /z/, the boundary was marked at the point of visible spectral discontinuity. Acoustic analysis was performed by the first and the third author. A subset of data (243 words or $8.3 \%$ of all data) was re-analysed by a third researcher, who was naïve to the purpose of the present study. The intraclass correlation coefficient for all three researchers was $0.96,95 \%$ CI [0.95; 0.97], $F(242,484)=80.42, p<$ 0.001 .

In total, 3,072 words were recorded (thirty-two participants' three repetitions of sixteen word pairs). Mean target sound durations were calculated from the three repetitions for each word for each participant. When a repetition was lost (for example, due to mispronunciation or a sudden background noise), mean durations were calculated from two repetitions. $2.54 \%$ of word pairs were lost because the participant failed to produce one or both words (22 consonant pairs and 17 vowel pairs). An additional $3.26 \%$ of word pairs (33 consonant and 17 vowel pairs) were excluded from the analysis because the participant spelled the target sound with the same number of letters (both with a single letter, or both with double letters). Since no effects of number of letters on sound production were expected if the participant did not know the spelling of the target sound, these pairs were later entered in a separate analysis reported below. Preliminary inspection of data revealed that the word pair these-cheese was anomalous, because bilinguals produced a longer vowel in these than in 
cheese. This happens because English $\mathrm{L}_{2}$ learners are explicitly instructed to produce a long vowel in these in order to differentiate it from singular this (Bassetti \& Atkinson, 2015). Since the long vowel in these is a washback effect of instruction, this anomalous pair was eliminated from the main analysis.

For each word pair, a duration ratio was calculated by dividing the duration of the sound spelled with double letters by the duration of the sound spelled with a single letter; for example dividing the duration of $[\mathrm{t}]$ in kitty by the duration of $[\mathrm{t}]$ in city. This was done to eliminate the potential confound of different speaking rates when comparing the two groups (Hirata \& Whiton, 2005) and to eliminate the potential effect of different intrinsic durations of English vowels (Peterson \& Lehiste, 1960). To remove outliers, the top and bottom 1\% of ratios were excluded (seven consonant pairs and four vowel pairs), and data was logarithmically transformed to eliminate skewness.

Statistical analysis was performed using R version 3.2.4 (R Core Team, 2016) with RStudio (RStudio Team, 2015) and additional packages lmertest (Kuznetsova, Brockhoff, \& Christensen, 2016), doBy (Højsgaard \& Halekoh, 2016) and ggplot2 (Wickham, 2009). Two maximal mixed effects models were created for consonant and vowel data (Barr, Levy, Scheepers, \& Tily, 2013), including the fixed effect of language background (native speakers, bilinguals), and random intercepts for participants and word pairs. Using backward model selection, each simplified model was compared to the previous one, and the model with the smallest AIC (Akaike's Information Criterion) was selected.

\section{Results}

\subsection{Consonant duration ratios}

The geometric mean of the $\mathrm{CC} / \mathrm{C}$ ratio (the duration of the same consonant when spelled with double letters and when spelled with a single letter, log-transformed) was 1.11 in the 
Japanese-English bilingual group $(95 \%$ CI $[1.07 ; 1.16])$, and close to one (1.01) in the native English group $(95 \%$ CI $[0.98 ; 1.04])$. This reflects the fact that descriptively the Japanese produced the same consonant as longer when spelled with double letters $\left(M_{C C \text {-words }}=90 \mathrm{~ms}\right.$, $S D=23)$ than with a single letter $\left(M_{C \text {-words }}=81 \mathrm{~ms}, S D=18\right)$, whereas the English speakers produced consonants of similar duration regardless of spelling $\left(M_{C C \text {-words }}=67 \mathrm{~ms}, S D=18\right.$; $\left.M_{C \text {-words }}=66 \mathrm{~ms}, S D=17\right)$.

Table 2 shows the final model and the results of the model. The CC/C ratio was higher among bilinguals than among native speakers, $p<0.001$. The random intercept of word pairs reflected the variation in ratios across word pairs.

Table 2. Results of mixed-model analysis of the effects of language background (Native English Speakers, Japanese-English Bilinguals) on logged consonant duration ratio. $R$ code: $\bmod C 2=\operatorname{lmer}\left(C C \_C \_R A T I O L o g \sim G R O U P+(1 \mid\right.$ WORDPAIR $)$, data=ProdDataCFinal, $R E M L=F A L S E)$.

\begin{tabular}{|c|c|c|}
\hline Random effects & Variance & $S D$ \\
\hline Word pair $\quad$ Intercept & 0.002 & 0.049 \\
\hline Residual & 0.032 & 0.179 \\
\hline
\end{tabular}

\begin{tabular}{llllll}
\hline Fixed effects & Estimate & $\boldsymbol{S E}$ & $\boldsymbol{d} \boldsymbol{f}$ & $\boldsymbol{t}$-value & $\boldsymbol{p}$ \\
\hline Intercept & 0.005 & 0.023 & 14.31 & 0.198 & 0.846 \\
Language background & 0.098 & 0.024 & 227.12 & 4.099 & $<0.001^{* * * *}$ \\
\hline
\end{tabular}

To confirm that the observed differences in consonant duration in the bilingual group were due to the number of letters in the consonant's spelling, a further analysis was performed on misspelled words. We compared the durations of the two target consonants in 
each word pair where both consonants had been spelled with the same number of letters. For instance we compared the duration of $[\mathrm{k}]$ in pairs that had been spelled $*<$ acuse $>-<$ acute $>$, or <accuse>-*<accute>. No durational differences were found in such word pairs, $M_{C \text {-words }}=96$ $\mathrm{ms}, S D=24 ; M_{C C \text {-words }}=97 \mathrm{~ms}, S D=26, t(11)=-0.15, p=0.887$.

To check whether consonant duration in English ${ }_{\mathrm{L} 2}$ words was affected by the pronunciation of English loanwords in Japanese, we looked at the $\mathrm{CC} / \mathrm{C}$ duration ratios of the two word pairs that contained an English $\mathrm{L}_{2}$ word that was a loanword in Japanese: floppy, which is produced with a geminate in Japanese, and kitty, which is produced with a singleton. Despite small descriptive differences in the predicted direction, the $\mathrm{CC} / \mathrm{C}$ duration ratio was neither larger in copy-floppy than in the other $/ \mathrm{p} / \mathrm{pairs}\left(M_{\text {copy-floppy }}=1.28, S D=0.11 ; M_{\text {other } / p /}\right.$ $=1.22, S D=0.16, t(12)=1.46, p=0.169)$, nor smaller in city-kitty than in the other $/ \mathrm{t} /$ pairs $\left(M_{\text {city-kitty }}=1.13, S D=0.18 ; M_{\text {other } / t /}=1.18, S D=0.22, t(15)=-0.74, p=0.472\right)$.

\subsection{Vowel duration ratios}

The geometric mean of the VV/V ratio (the duration of the same vowel when spelled with double letters and when spelled with a single letter, log-transformed) was 1.12 in the Japanese-English bilingual group (95\% CI $[1.08 ; 1.16])$, and 1.04 in the native English group

(95\% CI $[1.01 ; 1.06])$. This reflects the fact that descriptively the Japanese produced the same vowel as longer when spelled with double letters $\left(M_{V V \text {-words }}=293 \mathrm{~ms}, S D=62\right)$ than with a single letter $\left(M_{V \text {-words }}=264 \mathrm{~ms}, S D=62\right)$, whereas the English speakers produced vowels of similar duration regardless of spelling $\left(M_{V V \text {-words }}=285 \mathrm{~ms}, S D=69 ; M_{V \text {-words }}=275 \mathrm{~ms}, S D=\right.$ $67)$.

Table 3 shows the final model and the results of the model. The VV/V ratio was higher among bilinguals than among native speakers, $p=0.002$. 
Table 3. Results of mixed-model analysis of the effects of language background (Native English Speakers, Japanese-English Bilinguals) on logged vowel duration ratio. $R$ code: modV3=lmer $\left(V V_{-} V_{-} R A T I O L o g \sim G R O U P+(1 \mid S I D N O)\right.$, data=ProdDataVFinal, $R E M L=F A L S E)$.

\begin{tabular}{|c|c|c|}
\hline Random effects & Variance & $S D$ \\
\hline Participant Intercept & 0.0003 & 0.017 \\
\hline Residual & 0.017 & 0.129 \\
\hline
\end{tabular}

\begin{tabular}{lccccc}
\hline Fixed effects & Estimate & $\boldsymbol{S E}$ & $\boldsymbol{d} \boldsymbol{f}$ & $\boldsymbol{t}$-value & $\boldsymbol{p}$ \\
\hline Intercept & 0.037 & 0.014 & 25.26 & 2.583 & $0.016^{*}$ \\
Language background & 0.074 & 0.022 & 31.26 & 3.442 & $0.002^{* *}$ \\
\hline
\end{tabular}

A further analysis was performed on the words containing vowel targets that were misspelled by the Japanese-English bilinguals, as was done for the words with target consonants. No durational differences were found in the bilingual group's production of word pairs where the target sound had been spelled with the same number of letters $\left(M_{V \text {-words }}=215\right.$ ms, $\left.S D=50 ; M_{V V-\text { words }}=223, S D=27\right), t(9)=-0.83, p=0.427$.

\section{Discussion}

The aim of the present study was to test whether orthographic effects on L2 speech production are found in biscriptal bilinguals - bilinguals whose two languages use different scripts - and whether L2 orthographic forms - single or double letter spelling - affect L2 consonant and vowel duration in sequential bilinguals whose L1 has contrastive length in both consonants and vowels. As predicted, Japanese L1 $_{\text {-English }}$ L2 $_{2}$ sequential bilinguals systematically produced the same consonant or vowel as longer when orthographically 
represented with double letters than when represented with a single letter. As these L2 speakers were native users of a non-alphabetical script, unlike Italian participants in previous studies, they did not have a correspondence between double letters and long sounds in their native orthography. Results confirmed previous findings that L2 orthography can lead L2 speakers to establish two phonological categories - long and short - corresponding to one category in the target language (Bassetti, 2017; Bassetti et al., 2018). However, results also showed that orthographic effects are not restricted to the users of alphabetic writing systems, but are present in biscriptal bilinguals. There were no differences in the magnitude of orthographic effects in the Japanese-English bilingual group, as the duration ratio of the double-letter sound to the single-letter sound, calculated as the mean of individual ratios, was 1.14 for both consonants and vowels (with the exception of the anomalous pair these-cheese). Unlike Italian speakers of L2 English (Bassetti \& Atkinson, 2015), Japanese-English bilinguals show very similar effects in vowels and in consonants, most likely because vowel length is contrastive in Japanese, but not in Italian.

\subsection{Effect of number of letters on consonant duration}

The Japanese-English sequential bilinguals, but not the native English speakers, produced the same consonant as longer when spelled with double letters than when spelled with a single letter. Orthography affected these biscriptals' L2 consonant production, in line with previous findings from native users of the roman alphabet (Bassetti 2017; Bassetti et al., 2018).

This is arguably the first evidence that orthography affects L2 phonology in sequential bilinguals whose L1 writing system is not alphabetical. This shows that effects can take place across scripts, and in the absence of relevant GPCs in the L1 writing system. The few previous studies that investigated orthographic effects on phonology across scripts found little or no orthographic effects (Hayes-Harb \& Cheng, 2016; Pytlyk, 2011; Showalter \& 
Hayes-Harb, 2015). However, this absence of effects was probably due to lack of familiarity with the orthography or the phonology of the target language, as such studies investigated naïve learners of a novel language and orthography. The present study, by testing experienced users of two scripts, showed that orthographic effects can be found across scripts. Furthermore, Showalter and Hayes-Harb (2015) argued that the reason for the absence of orthographic effects in biscriptals is that such learners do not need to override native GPCs. In addition to that finding, the present results show that L2 phonology can be affected by orthography even when the L1 writing system does not have GPCs that can interfere with the recoding of the L2 orthographic forms. The Japanese-English biscriptals' L1 writing system does not represent gemination with double letters, as gemination is represented by a subscript $t s u$ symbol. These bilinguals establish a long-short contrast in their English $_{\mathrm{L} 2}$ phonological system, due to their L1 phonological system, and use English orthography (single or double letters) as a marker of length, even in the absence of such GPCs in their native orthography. The use of double letters to represent long consonants in romanised Japanese may play a role in this, but this cannot be considered a native GPC given that Japanese speakers hardly ever use romanisation. The effect of orthography on L2 phonology is therefore not restricted to native users of alphabetic writing systems, or to graphemes that can be decoded incorrectly due to native GPCs.

The orthographic nature of these effects was confirmed by the lack of orthographic effects in misspelled word pairs, that is to say, pairs in which the target consonant was erroneously spelled with the same number of consonant letters, as in acute-*acuse or *accute-accuse. The CC-consonant and the $\mathrm{C}$-consonant were produced with similar duration when the participant thought they were spelled with the same number of letters. This confirms the close relationship between L2 speakers' written and spoken production of L2 sounds. 
Although orthographic forms resulted in the production of a longer and a shorter form of the same consonant in English $\mathrm{L}_{2}$, the actual ratios were smaller than the ratios both in the participants' native language and in Italian ${ }_{\mathrm{L} 1}$ speakers of English $\mathrm{L}_{2}$, showing that the present ratios were probably caused by an interaction of orthographic input, phonological input, and the difference between English and Japanese scripts. First, the $\mathrm{CC} / \mathrm{C}$ ratio was on average 1.14 , which is smaller than the geminate/singleton ratio of two or more typically found in Japanese. This suggests that orthographic effects are weakened by the absence of confirmatory evidence in native spoken input, where there are no durational differences between consonants. Previous research had also found smaller ratios in English $\mathrm{L}_{2}$ than in the native language (Bassetti et al., 2018). Second, the CC/C ratio of these Japanese native speakers was smaller than the ratios previously found in Italian ${ }_{\mathrm{L} 1}$ speakers of English $_{\mathrm{L} 2 \text {, }}$ suggesting that orthographic effects may be weaker in biscriptal than in monoscriptal bilinguals. Previously reported mean ratios of 1.66 (Bassetti, 2017) and 1.70 (Bassetti et al., 2018) in instructed L2 learners could be due to learners' limited exposure to spoken input. However, Bassetti and colleagues (2018) reported a mean ratio of 1.38 in intervocalic consonants produced by Italian-English sequential bilinguals, who were roughly comparable to the present study's participants in terms of length of residence in England (on average six years for the Italians and five for the Japanese), as well as in other relevant factors such as age of onset of acquisition (both around eleven), length of instructed learning (both around 89 years), type of teachers (mostly non-native teachers) and language teaching practices (mostly textbook-based). Although it is not possible to compare the results of different studies (Bassetti, 2017, only tested learners; Bassetti et al., 2018, used different materials), differences in scripts may lead to a weaker impact of orthography in Japanese than in Italian speakers of English.

Results confirmed and extended a number of previous findings on orthographic 
effects on L2 speech production, as follows: First, results confirmed that L2 orthography affects L2 speakers who are native users of a phonologically transparent writing system (Erdener \& Burnham, 2005), and extended this to native users of a phonologically transparent non-alphabetic script. This is interesting because native Japanese speakers are often presented as typical examples of readers of an opaque orthography (see reviews in Koda, 2005, 2007), because kanji are phonologically opaque. However, it appears that L2 speakers who are native users of both a transparent script and an opaque one still rely on L2 orthographic forms. Future research could investigate speakers of various native languages to compare the effect of different levels of phonological transparency of the native orthography or orthographies. Second, results confirmed that orthography affects L2 phonology beyond the early stages of language learning, as effects were found in sequential bilinguals with nine and a half years of instruction and almost five years of residence in an English-speaking country. This confirms recent evidence that orthographic effects are found in L2 speakers with long experience of L2 learning (Bassetti, 2017) or with lengthy naturalistic exposure in a targetlanguage environment (Bassetti et al., 2018), and not only in beginners learners and naïve learners of novel languages (e.g., Zampini, 1994). Finally, there was much variation in the Japanese group in terms of proficiency, length of stay, and other variables reported in the participants' description. This is because our sample is representative of the varied population of native Japanese speakers living in the UK. Future research could investigate whether individual variables such as length of stay, proficiency and amounts of spoken and written input can impact the orthographic effects on speech production.

Further research is needed to establish whether the phonological forms of cognates and loanwords impact orthographic effects on L2 pronunciation. In this study durational ratios did not differ significantly between English double-letter words that were loanwords in Japanese and those that were not. If the phonological form of loanwords impacted gemination 
in English $\mathrm{L}_{2}$, there would have been stronger effects in the word floppy, whose loanword contains a geminate in Japanese, and weaker effects in the word kitty, whose loanword contains a singleton. No significant differences were found. However, previous studies found stronger gemination in Italian $\mathrm{L}_{1}$ speakers of English $\mathrm{L}_{2}$ when an L2 word was a loanword or a cognate containing a geminate in Italian, such as floppy (Bassetti, 2017) and Finnish (Italian finnico, Bassetti et al., 2018). Evidence is inconsistent, but it suggests that orthographic effects resulting in gemination may be reinforced by the presence of a geminate in cognates and loanwords in L1.

The effects of number of consonants on consonant duration in Japanese speakers of English $_{\mathrm{L} 2}$ cannot be explained by a single factor. Since gemination does not exist in English, and is not represented by double letters in Japanese, there may be various reasons why Japanese speakers produce double-letter English consonants as longer. Below we discuss: intra-orthographic effects (incorrectly assuming a correspondence between double letters and longer sound duration); effects of knowledge of other scripts (romaji); washback of teaching practices (furigana); and spoken input (from other Japanese speakers of English $\mathrm{L}_{2}$ and from English loanwords in Japanese).

An intra-orthographic effect explanation would be that Japanese speakers interpret double consonant letters in English orthography as a representation of longer sound length. As a result, they create $\langle\mathrm{CC}>-/ \mathrm{C}: /$ GPCs between double letters and geminates, which do not exist in either the target or the native language (e.g., $\langle\mathrm{pp}\rangle-/ \mathrm{p}: /)$. This would be similar to what native Italian speakers do, but it would be intra-orthographic (internal to English orthography), rather than inter-orthographic (caused by the incorrect application of native GPCs to their L2). This interpretation runs against the proposal by Showalter and Hayes-Harb (2015) that cross-scriptal orthographic effects on L2 phonology are unlikely if there are no L1 GPCs to override. Another explanation may be that Japanese native speakers are also literate 
in romaji, or romanised Japanese, which represents Japanese geminates using double letters. However, romaji by itself would not be a sufficient explanation, because Japanese speakers are unlikely to be affected by the GPCs of romaji, a script they use extremely rarely, more than by the GPCs of English, which they have been using for years. Other factors include: the presence of geminates in the phonological and orthographic (katakana) forms of English loanwords, which may misleadingly point to the presence of long and short consonants in English; the use of the supplementary script furigana which is used in schools for glossing the pronunciation of Japanese kanji and English words, and is considered the source of various nontarget-like productions (T. Okada, 2005). While it may well be impossible to pin down the cause or causes of these effects, it is clear that the main cause of gemination in Japanese speakers' English ${ }_{\mathrm{L} 2}$ speech production is the number of letters in English word spellings.

Finally, it should be noted that participants reported more exposure to written than spoken input, and this may partly explain why orthographic forms affect their speech production. While this study did not address this question, future research could investigate whether the amount of orthographic input impacts orthographic effects on L2 speech.

\subsection{Effect of number of letters on vowel duration}

The Japanese-English bilinguals, but not the native speakers, produced the same vowel as longer when spelled with double letters than when spelled with a single letter. This happened because these English $\mathrm{L}_{2}$ speakers overgeneralised the English language correspondence between single letter spelling and short vowel to contexts where it does not apply, whether to the single letter $<\mathrm{i}>$, which represents a long vowel in words such as $s k i(/ \mathrm{ski} /)$, or to the letter <e> in scene, which is in fact part of the grapheme <e_e>, which represents /ii:.

The mean VV/V duration ratio of 1.14 (excluding the anomalous pair these-cheese) was the same as the mean $\mathrm{CC} / \mathrm{C}$ duration ratio. This shows that number of letters has similar 
effects on the production of consonants and vowels in native speakers of a language that has contrastive length in both consonants and vowels. Previous studies of Italian speakers of L2 English found smaller ratios in vowels than in consonants (Bassetti et al., 2018), probably because Italian has contrastive length in consonants but not in vowels. The only exception to this pattern were the words these-cheese, whose vowel was produced with similar duration by both L1 and L2 speakers (this is because L2 participants produced a long vowel in these, as was reported by Bassetti and Atkinson, 2015).

The mean duration ratio of 1.14 is smaller than both the long/short vowel ratio of 2-3 normally found in Japanese, and the tense/lax ratio of 1.2-1.7 normally found in English (Hillenbrand, 1995; Kondaurova \& Francis, 2010; Leung et al., 2016; Peterson \& Lehiste, 1960; Williams \& Escudero, 2014). As in previous studies with Italian L1 speakers of English $_{\mathrm{L} 2}$, this smaller ratio is most likely due to the interference between the single vowel letters in the orthographic input, which are generally recoded as short vowels, and the long vowels in the spoken input. It is also possible that at least some of these L2 speakers may be aware that the grapheme $<$ V_e $>$ represents a long vowel in some of the present study's words such as scene. This possibility should be tested in future studies, and it would also be of interest to compare the duration of these orthography-induced shorter vowels with the duration of lax and tense English $\mathrm{L}_{2}$ vowels to establish whether they are as long as English $\mathrm{L}_{\mathrm{L}}$ lax vowels or constitute a third category with durations that are in-between those of lax and tense vowels.

The mean VV/V ratio is also smaller than the 1.20 ratio found in Italian $_{\mathrm{L1}}$-English $\mathrm{L}_{2}$ sequential bilinguals with lengths of residence comparable to those of the participants in the present study (Bassetti et al., 2018, results from double letter vowels; results differed for vowels spelled with digraphs such as <ou>). The mean ratio is however close to the ratio of 1.13 found in Italian $_{\mathrm{L} 1}$ learners of English $\mathrm{L}_{2}$ (Bassetti \& Atkinson, 2015). As with consonants, 
it is possible that the smaller orthographic effects in these Japanese-English bilinguals are due to their biscriptalism, as the effects of number of letters on the duration of L2 sounds could be weaker in non-alphabetic native readers.

\subsection{The locus of orthographic effects on L2 phonology}

With regards to the debate of whether orthographic effects on phonology are due to coactivation of orthographic and phonological codes during speech production (Muneaux \& Ziegler, 2004; Rastle, McCormick, Bayliss, \& Davis, 2011), or to effects of orthographic forms on phonological representations in L2 speakers' minds (Taft, 2006), the present findings strongly support the latter approach. Namely, our results are compatible with the idea that L2 phonological representations are generated during the L2 word learning process, through the interaction between L2 orthographic forms - often reinterpreted using native GPC rules - and L2 phonological forms - often reinterpreted according to the native phonology (Bassetti, 2008). In the case of Japanese bilinguals, double letters may be recoded as long sounds during the process of learning English words due to the various reasons discussed above (English GPCs, romaji, furigana). English orthographic forms would then result in phonological representations of English $\mathrm{L}_{2}$ words containing long consonants or vowels. At the same time, the native spoken input would provide conflicting evidence, whereby the word is heard with a short sound. This may be partially offset by spoken input from fellow Japanese speakers of English and from English loanwords. The complex interaction between orthographic and phonological input best explains why an EnglishL2 sound spelled with double letters is produced as longer than the same sound spelled with a single letter, but shorter than long sounds in the native language. To further clarify the role of orthographic forms in shaping phonological representations of L2 words, future research could investigate whether exposure to word spellings containing double letters during the 
early stages of spoken word learning leads English ${ }_{\mathrm{L} 2}$ speakers to learn L2 spoken words containing long sounds.

Whether the co-activation of orthographic and phonological forms also plays a role is a difficult question to answer. Bassetti (2017) stated that, in the case of Italian L2 speakers, orthographic effects would occur if the L2 orthographic form is activated together with L1 GPCs. However, this explanation does not apply to Japanese $\mathrm{L}_{1}-$ English $_{\mathrm{L} 2}$ speakers because there are no double letters in Japanese scripts. If orthographic forms are co-activated, then Japanese 1 -English $_{\text {L2 }}$ speakers must have established nonnative-like GPCs in English, whereby double letters correspond to long sounds. These nonnative-like GPCs could then be used to decode orthographic forms online and interfere with phonological representations as follows: If Japanese English 2 speakers' phonological representations contain short sounds, in line with phonological input they receive from native speakers, then co-activated orthographic forms may interfere if the L2 speakers have established nontarget-like English GPCs whereby double letters correspond to long sounds. If these speakers' phonological representations contain long sounds, then co-activated orthographic forms could reinforce the effects of the phonological forms. In either case, the present study confirms that L2 speech production is affected by the phonological systems and writing systems of both the target language and the native language(s), and it is very likely that orthographic forms affect the establishment of L2 phonological forms during the word learning process.

\section{Conclusions}

This study extends the growing body of research into orthographic effects on second language phonology by investigating these effects cross-scriptally. Results have implications for research on L2 phonology and for L2 teaching practice.

Regarding theories of orthographic effects on phonology, as discussed above, the 
present findings support the view that orthography affects the phonological representations of L2 words, even in native users of a non-alphabetic writing system. Furthermore, much L2 phonology research investigates L2 speakers who have a single phonological category corresponding to two target categories, but the present results confirm that L2 speakers can have two categories corresponding to a single target category (Bassetti, 2017). Third, effects of number of letters on vowel duration were found in the absence of orthographic input, confirming previous evidence from reading aloud tasks (Bassetti \& Atkinson, 2015; Bassetti et al., 2018).

With regards to the teaching of L2 pronunciation, teachers should be aware that L2 spellings can affect pronunciation in non-alphabetic L2 learners (e.g., Swan \& Smith, 2001, do not report spelling among factors influencing Japanese learners), and that orthography can affect sound length (an aspect of L2 phonology that is not discussed in materials for L2 pronunciation teachers, e.g., Swan \& Smith, 2001, do not mention gemination). Since the effects of L2 spellings on L2 phonology are still found in L2 speakers with years of naturalistic exposure, L2 teachers could consider this factor in their teaching practice. 


\section{References}

Aoyama, K., Flege, J. E., Guion, S., Akahane-Yamada, R., \& Yamada, T. (2004). Perceived phonetic dissimilarity and L2 speech learning: The case of Japanese /r/ and English /l/ and /r/. Journal of Phonetics, 32, 233-250.

Barr, D. J., Levy, R., Scheepers, C., \& Tily, H. J. (2013). Random effects structure for confirmatory hypothesis testing: Keep it maximal. Journal of Memory and Language, 68(3), 255-278.

Bassetti, B. (2007). Effects of hanyu pinyin on pronunciation in learners of Chinese as a foreign language. In A. Guder, X. Jiang, \& Y. Wan (eds.), The congnition, learning and teaching of Chinese characters, pp. 155-179. Beijing, China: Beijing Language and Culture University Press.

Bassetti, B. (2008). Orthographic input and second language phonology. In T. Piske \& M. Young-Scholten (eds.), Input matters in SLA, pp. 191-206. Clevedon, UK: Multilingual Matters.

Bassetti, B. (2017). Orthography affects second language speech: Double letters and geminate production in English. Journal of Experimental Psychology: Learning, Memory, and Cognition, 43, 1835-1842. doi: 10.1037/xlm0000417

Bassetti, B., \& Atkinson, N. (2015). Effects of orthographic forms on pronunciation in experienced instructed second language learners. Applied Psycholinguistics, 36, 6791. doi: 10.1017/S0142716414000435

Bassetti, B., Escudero, P., \& Hayes-Harb, R. (2015). Second language phonology at the interface between acoustic and orthographic input. In R. Hayes-Harb, B. Bassetti, \& P. Escudero (eds.), Orthographic effects in second langauge phonology. Special Issue. Applied Psycholinguistics (Vol. 36, pp. 1-6). 
Bassetti, B., Sokolović-Perović, M., Mairano, P., \& Cerni, T. (2018) Orthography-induced length contrasts in the second language phonological systems of L2 speakers of English: Evidence from minimal pairs. Language and Speech, 61(4), 577-597, doi: 10.1177/0023830918780141.

Boersma, P., \& Weenink, D. (2012). Praat: doing phonetics by computer [Computer program], Version 5.3.13 (retrieved April 11, 2012 from http://www.praat.org/).

Brown, C. A. (1998). The role of the L1 grammar in the L2 acquisition of segmental structure. Second Language Research, 14, 136-193.

Carney, E. (1994). A survey of English spelling. Oxford: Routledge.

Clark, J., \& Yallop, C. (1995). An introduction to phonetics and phonology. Oxford: Blackwell Publishing.

Cohen, J., MacWhinney, B., Flatt, M., \& Provost, J. (1993). PsyScope: An interactive graphic system for designing and controlling experiments in the psychology laboratory using Macintosh computers. Behavior Research Methods, Instruments \& Computers, 25, $257-271$.

Cook, V. J. (2002) Background to the L2 user. In V. J. Cook (Ed.) Portraits of the L2 user (pp. 1-28). Clevedon, UK: Multilingual Matters.

Coulmas, F. (2003). Writing systems: An introduction to their linguistic analysis. Cambridge: Cambridge University Press.

Davidson, L. (2010). Phonetic bases of similarities in cross-language production: Evidence from English and Catalan. Journal of Phonetics, 38, 272-288.

Detey, S., \& Nespoulous, J. L. (2008). Can orthography influence second language syllabic segmentation? Japanese epenthetic vowels and French consonantal clusters. Lingua, 118, 66-81. doi: 10.1016/j.lingua.2007.04.003 
Dupoux, E., Kakehi, K., Hirose, Y., Pallier, C., \& Mehler, J. (1999). Epenthetic vowels in Japanese: A perceptual illusion? Journal of Experimental Psychology: Human Perception and Performance, 25, 1568-1578.

Erdener, V. D., \& Burnham, D. K. (2005). The role of audiovisual speech and orthographic information in nonnative speech production. Language Learning, 55, 191-228.

Escudero, P. (2015). Orthography plays a limited role when learning the phonological forms of new words: The case of Spanish and English learners of novel Dutch words. Applied Psycholinguistics, 36, 7-22.

Escudero, P., Hayes-Harb, R., \& Mitterer, H. (2008). Novel second-language words and asymmetric lexical access. Journal of Phonetics, 36, 345-360.

Escudero, P., Simon, E., \& Mulak, K. E. (2014). Learning words in a new language: Orthography doesn't always help. Bilingualism: Language and Cognition, 17, 384395.

Escudero, P., \& Wanrooij, K. (2010). The effect of L1 orthography on non-native vowel perception. Language and Speech, 53, 343-365.

Flege, J. E., Munro, M. J., \& MacKay, I. R. A. (1995). Factors affecting strength of perceived foreign accent in a second language. The Journal of the Acoustical Society of America, 97, 3125-3134.

Foulkes, P., Docherty, G., \& Jones, M. (2010). Analysing stops. In M. Di Paolo \& M. Yaeger-Dror (eds.), Sociophonetics: a student's guide, pp. 58-71. London: Routledge.

Foulkes, P., \& Docherty, G. J. (2006). The social life of phonetics and phonology. Journal of Phonetics, 34, 409-438.

Hayes-Harb, R., \& Cheng, H.-W. (2016). The Influence of the pinyin and zhuyin writing systems on the acquisition of Mandarin word forms by native English speakers. Frontiers in Psychology, 7: 785. 
Hayes-Harb, R., Nicol, J., \& Barker, J. (2010). Learning the phonological forms of new words: Effects of orthographic and auditory input. Language and Speech, 53, 367381.

Hillenbrand. (1995). Acoustic characteristics of American English vowels. The Journal of the Acoustical Society of America, 97, 3099-3111.

Hirata, Y. (2004). Effects of speaking rate on the vowel length distinction in Japanese. Journal of Phonetics, 32, 565-589.

Hirata, Y., \& Tsukada, K. (2009). Effects of speaking rate and vowel length on formant frequency displacement in Japanese. Phonetica, 66, 129-149.

Hirata, Y., \& Whiton, J. (2005). Effects of speaking rate on the single/geminate stop distinction in Japanese. The Journal of the Acoustical Society of America, 118, 16471660.

Højsgaard, S., \& Halekoh, U. (2016). doBy: Groupwise Statistics, LSmeans, Linear Contrasts, Utilities. R package version 4.5-15. Retrieved from https://CRAN.Rproject.org/package $=\mathrm{doBy}$.

Idemaru, K., \& Guion, S. G. (2008). Acoustic covariants of length contrast in Japanese stops. Journal of the International Phonetic Association, 38, 167-186.

Irwin, M. (2011). Loanwords in Japanese. Amsterdam/Philadelphia: John Benjamins Publishing.

Kawagoe, I. (2015). The phonology of sokuon, or geminate obstruents. In H. Kubozono (ed.), Handbook of Japanese phonetics and phonology, pp. 79-119. Berlin: de Gruyter.

Kawahara, S. (2015). The phonetics of sokuon, or geminate obstruents. In H. Kubozono (ed.), Handbook of Japanese phonetics and phonology, pp. 43-77. Berlin: de Gruyter.

Keating, P. A., Linker, W., \& Huffman, M. (1983). Patterns in allophone distribution for voiced and voiceless stops. Journal of Phonetics, 11, 277-290. 
Koda, K. (2005). Learning to read across writing systems: Transfer, metalinguistic awareness, and second-language reading development. In V. J. Cook \& B. Bassetti (eds.), Second language writing systems, pp. 311-334. Clevedon, UK: Multilingual Matters.

Koda, K. (2007). Reading and language learning: Crosslinguistic constraints on second language reading development. Language Learning, 57 (Supplement 1), 1-44.

Kondaurova, M. V., \& Francis, A., L. (2010). The role of selective attention in the acquisition of English tense and lax vowels by native Spanish listeners: comparison of three training methods. Journal of Phonetics, 38, 569-587. doi:

10.1016/j.wocn.2010.08.003

Kubozono, H. (2015a). Intoduction to Japanese phonetics and phonology. In H. Kubozono (ed.), Handbook of Japanese Phonetics and Phonology, pp. 1-40. Berlin: de Gruyter. Kubozono, H. (2015b). Loanword phonology. In H. Kubozono (ed.), Handbook of Japanese Phonetics and Phonology, pp. 313-361. Berlin: de Gruyter.

Kuznetsova, A., Brockhoff, P. B., \& Christensen, R. H. B. (2016). lmerTest: Tests in linear mixed effects models. Retrieved from https://CRAN.R-project.org/package=lmerTest.

Laburne, L. (2012). The phonology of Japanese Oxford, UK: Oxford University Press.

Ladefoged, P., \& Johnson, K. (2011). A course in phonetics (6th ed.). Boston, MA: Wadsworth/Cengage.

Laver, J. (1994). Principles of phonetics. Cambridge: Cambridge University Press.

Leung, K. K. W., Jongman, A., Wang, Y., \& Sereno, J. A. (2016). Acoustic characteristics of clearly spoken English tense and lax vowels. The Journal of the Acoustical Society of America, 140, 45-58. doi: http://dx.doi.org/10.1121/1.4954737 
Muneaux, M., \& Ziegler, J. (2004). Locus of orthographic effects in spoken word recognition: Novel insights from the neighbour generation task. Language and cognitive processes, 19, 641-660.

Nimz, K. (2016). Sound perception and production in a foreign language. Does orthography matter? Universitätsverlag Potsdam, Germany.

Okada, H. (1999). Japanese. Handbook of the International Phonetic Association, pp. 117119. Cambridge: Cambridge University Press.

Okada, T. (2005). Spelling errors made by Japanese EFL writers: With reference to errors occurring at the word-initial and the word-final position. In V. J. Cook \& B. Bassetti (eds.), Second language writing systems, pp. 164-183. Clevedon, UK: Multilingual Matters.

Okada, T. (2015). Japanese uses of the English writing system: A case study. In V. J. Cook \& D. Ryan (eds.), The Routledge Handbook of the English Writing System, pp. 399-415. Oxford, UK: Routledge.

Otaka, H. (2009). Phonetics and phonology of moras, feet, and geminate consonants in Japanese. Plimouth, UK: University Press of America.

Otake, T. (2015). Mora and mora-timing. In H. Kubozono (ed.), Handbook of Japanese phonetics and phonology, pp. 493-523. Berlin: de Gruyter.

Peterson, G. E., \& Barney, H. L. (1952). Control methods used in a study of the vowels. Journal of the Acoustical Society of America, 24, 175-184.

Peterson, G. E., \& Lehiste, I. (1960). Duration of syllable nuclei in English. The Journal of the Acoustical Society of America, 32, 693-703.

Piske, T., Flege, J. E., MacKay, I. R. A., \& Meador, D. (2002). The production of English vowels by fluent early and late Italian-English bilinguals. Phonetica, 59, 49-71. 
Pytlyk, C. (2011). Shared orthography: Do shared written symbols influence the perception of L2 sounds? The Modern Language Journal, 95, 541-557.

R Core Team. (2016). R: A language and environment for statistical computing. Vienna, Austria: R Foundation for Statistical Computing. Retrieved from https://www.Rproject.org.

Rafat, Y. (2016). Orthography-induced transfer in the production of English-speaking learners of Spanish. The Language Learning Journal, 44, 197-213.

Rastle, K., McCormick, S. F., Bayliss, L., \& Davis, C. J. (2011). Orthography influences the perception and production of speech. Journal of Experimental Psychology: Learning, Memory, and Cognition, 37, 1588-1594. doi: 10.1037/a0024833

Roach, P. (2004). British English: Received Pronunciation. Journal of the International Phonetic Association, 34, 239-245.

RStudio Team. (2015). RStudio: Integrated development for R. Boston, MA: RStudio Inc. Retrieved from http://www.rstudio.com.

Sheldon, A., \& Strange, W. (1982). The acquisition of /r/ and /l/ by Japanese learners of English: Evidence that speech production can precede speech perception. Applied Psycholinguistics, 3, 243-261.

Showalter, C. E. (2018) Impact of Cyrillic on native English speakers' phono-lexical acquisition of Russian. Language and Speech, 61(4):565-576. doi: $10.1177 / 0023830918761489$.

Showalter, C. E., \& Hayes-Harb, R. (2013). Unfamiliar orthographic information and second language word learning: A novel lexicon study. Second Language Research, 29, 185200. 
Showalter, C. E., \& Hayes-Harb, R. (2015). Native English speakers learning Arabic: The influence of novel orthographic information on second language phonological acquisition. Applied Psycholinguistics, 36, 23-42.

Simon, E., Chambless, D., \& Alves, U. K. (2010). Understanding the role of orthography in the acquisition of a non-native vowel contrast. Language Sciences, 32, 380-394.

Simonchyk, A., \& Darcy, I. (2018). The effect of orthography on the lexical encoding of palatalized consonants in L2 Russian. Language and Speech, 61(4):522-546, doi: 10.1177/0023830918761490.

Swan, M., \& Smith, B. (eds.). (2001). Learner English: A teacher's guide to interference and other problems. Cambridge, UK: CUP.

Taft, M. (2006). Orthographically influenced abstract phonological representation: Evidence from non-rhotic speakers. Journal of Psycholinguistic Research, 35, 67-78.

Tsukada, K. (2009a). An acoustic comparison of vowel length contrasts in Arabic, Japanese and Thai: Durational and spectral data. International Journal on Asian Language Processing, 19, 127-138.

Tsukada, K. (2009b). Durational characteristics of English vowels produced by Japanese and Thai second language (L2) Learners. Australian Journal of Linguistics, 29, 287-299.

Turk, A., Nakai, S., \& Sugahara, M. (2006). Acoustic segment durations in prosodic research: a practical guide. In S. Sudhoff, D. Lenertova, R. Meyer, S. Pappert, P. Augurzky, I. Mleinek, N. Richter, \& J. Schlieser (eds.), Methods in empirical prosody research, pp. 1-28. Berlin, New York: De Gruyter.

Ueyama, M. (2000). Prosodic transfer: An acoustic study of L2 English vs. L2 Japanese. University of California Los Angeles. 
Ueyama, M. (2003). Duration and Quality in the Production of the Vowel Length Contrast in L2 English and L2 Japanese. Paper presented at the International Congress of Phonetic Sciences (ICPhS), Barcelona.

Vokic, G. (2011). When alphabets collide: Alphabetic first-language speakers' approach to speech production in an alphabetic second language. Second Language Research, 27, $391-417$.

Wickham, H. (2009). ggplot2: Elegant graphics for data analysis. New York: SpingerVerlag.Retrieved from http://ggplot2.org.

Williams, D., \& Escudero, P. (2014). A cross-dialectal acoustic comparison of vowels in Northern and Southern British English. The Journal of the Acoustical Society of America, 136, 2751-2761. doi: http://dx.doi.org/10.1121/1.4896471

Young-Scholten, M. (2002). Orthographic input in L2 phonological development. In P. Burmeister, T. Piske, \& A. Rohde (eds.), An integrated view of language development: Papers in honour of Henning Wode, pp. 263-279. Trier: Wissenschaftlicher Verlag Trier.

Young-Scholten, M., \& Langer, M. (2015). The role of orthographic input in second language German: Evidence from naturalistic adult learners' production. Applied Psycholinguistics, 36, 93-114.

Zampini, M. L. (1994). The role of native language transfer and task formality in the acquisition of Spanish spirantization. Hispania, 77, 470-481. 


\section{Appendix}

Table 1. Target consonants, target word pairs and carrier phrases used in the present study, including phonological and orthographic forms of target words.

\begin{tabular}{|c|c|c|c|}
\hline $\begin{array}{c}\text { Target } \\
\text { C }\end{array}$ & $\begin{array}{l}\text { Phonological } \\
\text { form }\end{array}$ & $\begin{array}{l}\text { Orthographic } \\
\text { form }\end{array}$ & $\begin{array}{c}\text { Carrier phrase } \\
\text { (target words underlined) }\end{array}$ \\
\hline \multirow[t]{2}{*}{$/ \mathrm{p} /$} & /'kppi/ & copy & Could I have a copy please? \\
\hline & /'flppi/ & floppy & Take a CD or a floppy. \\
\hline \multirow[t]{2}{*}{$/ \mathrm{p} /$} & /'ræpıdli/ & rapidly & Today the world is changing rapidly. \\
\hline & /'hæpıli// & happily & A group of happily married couples. \\
\hline \multirow[t]{2}{*}{$/ \mathrm{p} /$} & /'wepən/ & weapon & This is a very ancient weapon. \\
\hline & /'pepə/ & pepper & Salt and pepper, oil and vinegar. \\
\hline \multirow[t]{2}{*}{$/ \mathrm{t} /$} & $/$ 'siti/ & city & They both work in the city. \\
\hline & /'kıti/ & kitty & My god, a Hello Kitty room. \\
\hline \multirow[t]{2}{*}{$/ \mathrm{t} /$} & /'lætın/ & Latin & She studies Greek and Latin poetry. \\
\hline & /'tfætıy/ & chatting & She is chatting on the phone. \\
\hline \multirow[t]{2}{*}{$/ \mathrm{t} /$} & /'vitəminz/ & vitamins & This drink contains vitamins and sugar. \\
\hline & /'litərıy/ & littering & No littering, take your litter home. \\
\hline \multirow[t]{2}{*}{$/ \mathrm{k} /$} & /a'kjuit/ & acute & We both felt an acute pain. \\
\hline & /a'kju:z/ & accuse & I don't want to accuse anyone. \\
\hline \multirow[t]{2}{*}{$/ \mathrm{k} /$} & /'dpkjəment/ & document & Please look at this document here. \\
\hline & /'pkjəpai/ & occupy & How do you occupy your time? \\
\hline \multirow[t]{2}{*}{$/ \mathrm{k} /$} & /,nIkə'rægjuə/ & Nicaragua & I have friends from Peru and Nicaragua. \\
\hline & /_prkə'dıli/ & Piccadilly & An expensive shop near Piccadilly Circus. \\
\hline
\end{tabular}


Table 2. Target vowels, target word pairs and carrier phrases used in the present study, including phonological and orthographic forms of target words.

\begin{tabular}{|c|c|c|c|}
\hline $\begin{array}{c}\text { Target } \\
\text { V }\end{array}$ & $\begin{array}{l}\text { Phonological } \\
\text { form }\end{array}$ & $\begin{array}{l}\text { Orthographic } \\
\text { form }\end{array}$ & $\begin{array}{c}\text { Carrier phrases } \\
\text { (target words underlined) }\end{array}$ \\
\hline \multirow[t]{2}{*}{ /i:/ } & /tfar'ni:z/ & Chinese & This is a Chinese computer game. \\
\hline & /trei'ni:z/ & trainees & He is training four trainees. \\
\hline \multirow[t]{2}{*}{ /i:/ } & $/ \operatorname{si}: n /$ & scene & The balcony scene in Romeo and Juliet. \\
\hline & /si:n/ & seen & Have you seen my glasses? \\
\hline \multirow[t]{2}{*}{ /i:/ } & /bi:/ & $\mathrm{B}$ & The first letter of bravo is $\underline{B}$. \\
\hline & /bi:/ & bee & Inside the flower, there is a bee. \\
\hline \multirow[t]{2}{*}{ /i:/ } & /si:/ & $\mathrm{C}$ & The first letter of Charlie is $\underline{\mathrm{C}}$. \\
\hline & /si:/ & see & Can you see where he is? \\
\hline \multirow[t]{2}{*}{ /i:/ } & /ði:z/ & these & Look at these books here. \\
\hline & $/ \mathrm{t} \mathrm{ji}: \mathrm{z} /$ & cheese & I love ham and cheese sandwiches. \\
\hline \multirow[t]{2}{*}{$10: /$} & /mo:/ & more & He has more money than I have. \\
\hline & /do:/ & door & Who is knocking at the door? \\
\hline \multirow[t]{2}{*}{ /ui:/ } & /dzu:n/ & June & We went to Poland in June. \\
\hline & /mu:n/ & moon & The moon is white and round. \\
\hline
\end{tabular}

